\title{
Model Pentahelix Dalam Mengembangkan Potensi Wisata di Kota Pekanbaru
}

\author{
Resa Vio Vani'), Sania Octa Priscilia' ${ }^{2)}$, Adianto ${ }^{3)}$ \\ 1)Program Studi Administrasi Publik, Fakultas Ilmu Sosial dan Ilmu Politik, Universitas Riau, \\ Indonesia \\ 2)Program Studi Administrasi Publik, Fakultas Ilmu Sosial dan Ilmu Politik, Universitas Riau, \\ Indonesia \\ 3)Program Studi Administrasi Publik, Fakultas Ilmu Sosial dan Ilmu Politik, Universitas Riau, \\ Indonesia,
}

\begin{abstract}
Abstrak
Tuntutan perkembangan zaman baik di era disrupsi maupun revolusi industry 4.0 memaksa setiap elemen pada suatu negara untuk ikut andil dalam melakukan pengembangan dan pembaharuan. Stakeholder dituntut untuk bekerjasama dalam merealisasikan kebijakan yang dibuat oleh pemerintah demi tercapainya visi misi negara khususnya kota Pekanbaru yang saat ini memiliki visi Smart City Madani. Pekanbaru merupakan kota yang memiliki peningkatan presentase investor yang cukup signifikan, terbukti dengan munculnya pusat perbelanjaan dan objek rekreasi yang besar dan menciptakan sumber lapangan pekerjaan bagi masyarakat sekitar. Hal ini menjadi krusial ketika pengelolaan wilayah Kota Pekanbaru terkoordinir dengan baik oleh pemerintah dengan dukungan pihak swasta dan masyarakat. Maka dari itu untuk menjamin hal tersebut penulis melakukan penelitian yang bertujuan untuk menganalisis proses pengembangan potensi pariwisata di Kota Pekanbaru menggunakan model pentahelix, dengan menggunakan metode penelitian kualitatif. Hasil Penelitian ini membuktikan bahwa potensi wisata di Kota Pekanbaru dapat berkembang dengan pesat apabila seluruh stakeholder berkolaborasi dengan baik dilihat dari korelasi antar unsur model pentahelix.
\end{abstract}

Kata Kunci: Pentahelix, Pengembangan, Potensi Wisata

\begin{abstract}
The demands of the times both in the era of disruption or the industrial revolution 4.0 pushed every element of the country to take part in developing and renewing. Stakeholders are required to focus on policies made by the government to achieve the vision and mission of the state of Pekanbaru which currently has the vision of the Smart City Madani. Pekanbaru is a city that has an increased percentage, significant investors, as evidenced by shopping centers and large tourist attractions and create a source of employment for the surrounding community. This is crucial to the compilation of the management of the Pekanbaru City area which is well coordinated by the government with the support of the private sector and the community. Therefore to ensure that the authors conducted research aimed at analyzing the development of potential in the city of Pekanbaru using the pentahelix model, using qualitative research methods. The results of this study prove that the tourism potential in Pekanbaru City can develop successfully as expected by stakeholders who collaborate well. Judging from the considerations between the nonpentahelix models.
\end{abstract}

Keywords: Pentahelix, Development, Tourism Potential

How to Cite: Vani, V.R, Priscilia, O.S, \& Adianto. (2020). Model Pentahelix dalam Mengembangkan Potensi Wisata di Kota Pekanbaru. PUBLIKAUMA: Jurnal Ilmu Administrasi Publik UMA, Vol 8 (1): 63-70

*Corresponding

ISSN 2549-9165 (Print)

E-mail: resavani31@gmail.com

ISSN 2580-2011 (Online) 


\section{PENDAHULUAN}

Sustainable development goals menjadi acuan utama bagi negara-negara dunia pada tahun 2030 mewujudkan SDG's dengan model mutakhir atau yang bisa disebut model nested. Model ini melihat hubungan ekonomi, sosial, dan lingkungan secara komprehensif, yakni ekonomi merupakan bagian dari sosial dan sosial merupakan bagian dari lingkungan yang saling berkesinambungan (Prihati, 2017).

Maka dari itu model nested pada SDGs menjelaskan bahwa tidak ada tujuan yang terpisah antar ketiga aspek tersebut. Hal ini membuktikan bahwa lingkungan termasuk satu dari enam elemen esensial SDGs yakni Planet (planet), People (Manusia), Dignity (Marwah), Prosperity (Kesejahteraan), Justice (Keadilan), dan Partnership (Kemitraan) yang mempengaruhi aktivitas masyarakat salah satunya pada potensi pariwisata.

Adanya sektor pembangunan yang mendapat perhatian pemerintah untuk terus dikembangkan sampai saat ini, salah satunya pariwisata berkelanjutan yang dinilai cukup berpotensi meningkatkan perekonomian masyarakat. Potensi ini didasarkan atas kekhasan social budaya masyarakat, kondisi geografis dan keindahan alam yang potensial dalam pengembangan sektor wisata (Ismayanti, 2011).
Indonesia terdiri atas gugusan pulaupula sehingga semakin menambah peluang untuk menciptakan berbagai ciri khas berbeda di setiap daerah dalam mengembangkan sektor pariwisatanya, begitu juga dengan daerah Kota Pekanbaru Provinsi Riau. Sesuai dengan kebijakan Peraturan Daerah nomor 13 tahun 2000 tentang Promosi Pariwisata Daerah Kota Pekanbaru bahwa pengembangan pariwisata adalah kepentingan yang diserahkan Pemerintah Provinsi Riau kepada Pemerintah Kota Pekanbaru untuk melakukan promosi pariwisatanya (Gde, 2009).

Di dalam Undang-Undang No 33 tahun 2004 tentang Perimbangan Keuangan antara Pusat dan Daerah pasal 1 angka 18 dikatakan bahwa Pendapatan Asli Daerah (PAD), merupakan pendapatan yang diperoleh daerah yang dipungut berdasarkan peraturan daerah sesuai dengan peraturan perundangundangan. Dalam pandangan ekonomi sektor ini memiliki jaringan ke depan (forward linkage) yang luas apabila dikembangkan, karena akan dapat menumbuhkan industri pariwisata serta dampaknya bagi pembangunan ekonomi masyarakat yang melibatkan cukup banyak tenaga kerja dan berorientasi global.

Tabel 1. Target Kinerja Dinas Pariwisata Provinsi Riau Tahun 2019

\begin{tabular}{|c|c|c|}
\hline $\begin{array}{c}\text { Urusan/Bidang Urusan } \\
\text { Pemerintahan Daerah dan } \\
\text { Program / Kegiatan }\end{array}$ & $\begin{array}{c}\text { Indikator Kinerja Program } \\
\text { (outcomes) / Kegiatan (output) }\end{array}$ & $\begin{array}{c}\text { Target Kinerja Capaian } \\
\text { Program (Renstra Perangkat } \\
\text { Daerah ) Tahun 2019 }\end{array}$ \\
\hline $\begin{array}{c}\text { Program Pengembangan } \\
\text { Pemasaran Pariwisata }\end{array}$ & $\begin{array}{c}\text { Jumlah Kunjungan Wisatawan } \\
\text { Mancanegara. }\end{array}$ & 6.070 .297 .320 \\
\hline $\begin{array}{c}\text { Analisa Pasar Untuk Promosi dan } \\
\text { Pemasaran Pariwisata }\end{array}$ & $\begin{array}{c}\text { Jumlah potensi pasar pariwisata } \\
\text { yang dianalisis }\end{array}$ & 430.000 .000 \\
\hline $\begin{array}{c}\text { Pembuatan Video Profil } \\
\text { Pariwisata Daerah }\end{array}$ & $\begin{array}{c}\text { Tersedianya Video Profil/Film } \\
\text { Dokumenter tentang pariwisata } \\
\text { Provinsi Riau }\end{array}$ & \\
\hline $\begin{array}{c}\text { Pelaksanaan Koordinasi } \\
\text { Pembangunan Kemitraan } \\
\text { Pariwisata }\end{array}$ & - & - \\
\hline Pembinaan Duta Wisata & - & - \\
\hline
\end{tabular}

Sumber: Rencana Kerja SKPD Tahun 2019

Berdasarkan Rencana kerja SKPD tahun 2019 pada Bab 2 yakni evaluasi pelaksanaan Renja SKPD tahun 2017 membuktikan bahwa pada bagian pembuatan video profil pariwisata daerah, pelaksanaan koordinasi pembangunan kemitraan pariwisata dan pembinaan duta wisata masih belum terealisasikan. Maka dari itu penelitian ini merujuk pada realisasi kolaborasi antar 
seluruh stakeholder di bidang pariwisata khususnya Kota Pekanbaru.

Pada saat ini wisata berbasis kearifan lokal adalah prioritas utama dalam promosi yang dilakukan untuk meningkatkan jumlah wisatawan datang ke Kota Pekanbaru dan potensi pengembangan objek wisata dengan aksen budaya melayu tidak dimiliki oleh daerah lain. Dibawah ini tabel jumlah wisatawan mancanegara yang masuk ke Kota Pekanbaru.

Tabel 2. Perbandingan Jumlah Wisatawan Mancanegara di Kota Pekanbaru

\begin{tabular}{|l|c|c|c|c|}
\hline No & Tahun & Jumlah total & Selisih (+/-) & $\begin{array}{c}\text { Persentase } \\
-0,64 \% \\
(2011-2012) \\
+3,53 \%\end{array}$ \\
\hline 2 & 2011 & 25.227 & $-(162)$ & $+(884)$ \\
$(2012-2013)$
\end{tabular}

Sumber: Dinas Kebudayaan dan Pariwisata Kota Pekanbaru, 2019

Indonesia Nomor 14 Tahun 2016 Tentang

Tabel 2. Merupakan perbandingan kalkulasi Wisatawan Mancanegara yang mengunjungi Kota Pekanbaru pada tahun 2011-2012 mengalami penurunan sejumlah 162 jiwa dan mengalami peningkatan, yaitu tahun 2012 - 2013 sejumlah 884 jiwa kemudian pada tahun 2013-2014 mengalami penurunan sejumlah 192 jiwa selanjutnya pada tahun 2014-2015 mengalami penurunan 32 jiwa kemudian pada tahun 2015-2016 kembali mengalami penurunan sejumlah 821 jiwa. Analisis peneliti sejauh ini selisih perbandingan antara penurunan dengan peningkatan yaitu 4 berbanding 1 , dari pengamatan yang dilakukan peneliti, adanya penurunan jumlah wisatawan disebabkan oleh kurangnya informasi wisata terbaru dan promosi yang kurang dari sisi Pemerintah Kota Pekanbaru serta tempat wisata alam yang kurang memadai memaksa membangun tempat wisata baru menarik yang layak dikembangkan.

Salah satu solusi yang hadir sebagai strategi yang dicanangkan oleh pemerintah Kota Pekanbaru dalam pengembangan obejk wisata adalah melalui kolaborasi Model Pentahelix. Konsep kolaborasi yang pertama kali diperkenalkan oleh menteri pariwisata pada saat itu, Arief Yahya yang terdapat dalam Peraturan Menteri Pariwisata Republik Pedoman Destinasi Pariwisata Berkelanjutan bahwa pentingnya dorongan sistem kepariwisataan melalui optimasi peran business (Bisnis), government (Pemerintah), community (Komunitas), academic (Akademisi), and media (Publikasi) atau di singkat BGCAM agar terintegrasi dengan baik dan menciptakan kualitas aktivitas, fasilitas, pelayanan, serta pengalaman dan nilai manfaat kepariwisataan agar memberikan keuntungan dan manfaat pada masyarakat dan lingkungan.

Dari penyataan diatas, kolaborasi sangat dibutuhkan dalam rangka perlibatan secara bersama-sama dalam mengembangkan obyek pariwisata semaksimal mungkin dari kolaborasi antar elemen yang terkait langsung dengan industri pariwasata karena setiap elemen memiliki kompetensi khas sehingga hal tersebut sangat dibutuhkan dalam pengembangan pariwisata yang lebih baik.

\section{METODE PENELITIAN}

Jenis penelitian ini adalah kualitatif. Penelitian kualitatif adalah penelitian yang sifatnya deskriptif dengan menggunakan analisis. Mengedepankan proses dan perspektif subjek. Landasan teori dimanfaatkan sebagai panduan agar fokus penelitian selaras dengan fakta yang ada di lapangan (Cresswell, 2016). Disamping itu juga 
penelitian kualitatif dimaksudkan untuk mencatat seluruh fenomena yang dilihat dan didengar serta dibaca melalui wawancara atau bukan, catatan lapangan, foto, video tape, dokumen pribadi atau memo, dokumen resmi atau bukan, dan lainlain, dan peneliti harus membandingkan, mengkombinasikan, mengabstraksikan, dan menarik kesimpulan (Bungin, 2008). Selanjutnya dapat dilakukan analisa data melalui pengorganisasian data, dengan cara memilahnya menjadi satuan yang dapat dikelola, mensintesiskannya, mencari dan menemukan pola, menemukan apa yang penting dan apa yang dipelajari dan memutuskan apa yang dapat dijadikan temuan dan kesimpulan.

\section{HASIL DAN PEMBAHASAN}

Dinas Pariwisata Provinsi Riau berusaha melakukan kegiatan penggalian dan pengembangan wisat dengan tujuan peningkatan jumlah tempat wisata yang ada dan terhadap jumlah peminat wisatawan baik lokal maupun mancanegara. Potensi wisata daerah yang ada banyak tersedia di setiap Kabupaten/Kota. Hanya saja pengelolaan dan pengembangannya kurang maksimal dari unit kerja terkait.

Selain menonjol dalam bidang hospitality, Pekanbaru akan mengembangkan obyek wisata sejarah dan budaya contohnya seperti Pekanbaru Heritage Walk, wisatawan dapat mendatangi dan berkeliling ke tempattempat bersejarah yang ada di Pekanbaru. Seperti Rumah Singgah Sultan yang berada di pinggir Sungai Siak.

Dinas Kebudayaan dan Pariwisata Kota Pekanbaru akan fokus pada proses pengoptimalan dan pengembangan 3 objek wisata unggulan di Kota Pekanbaru pada tahun 2019. Tiga destinasi wisata tersebut yakni : wisata Danau Bandar Khayangan yang berada di Kecamatan Rumbai Pesisir, Wisata Dakwah Okura yang juga berada di Kecamatan Rumbai Pesisir, serta Wisata Heritage Sungai Siak yang berada di kawasan Kampung Bandar Kecamatan Senapelan. Dengan menggunakan strategi kolaborasi Model Pentahelix.

\section{Model Pentahelix}

Menurut (Soemaryani, 2016) Model pentahelix merupakan referensi dalam pengembangan sinergitas antara instansi untuk mencapai tujuan. Menurut (Rampersad, Quester, \& Troshani, dalam Halibas, Sibyan, dan Maat, 2017) peran kolaborasi pentahelix memiliki tujuan inovasi dan berkontribusi terhadap kemajuan sosial ekonomi daerah.

Selanjutnya (Aribowo, 2019) mengatajan bahwa dalam menciptakan orkestrasi dan memastikan kualitas aktivitas, fasilitas, pelayanan, menciptakan pengalaman serta nilai manfaat kepariwisataan demi memberikan keuntungan dan manfaat pada masyarakat dan lingkungan sekitar, maka diperlukan pendorong sistem kepariwisataan melalui optimasi peran business (bisnis), government (pemerintah), community (komunitas), academic (akademisi), and media (publikasi media) atau BGCAM.

Gambar 1. Model Pentahelix

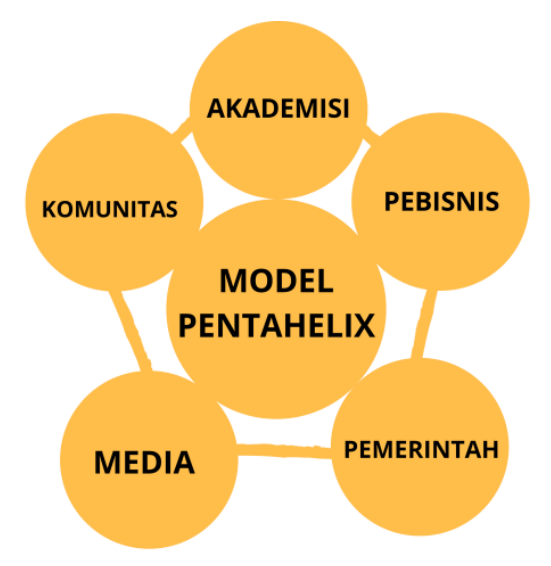

Sumber : Olahan Peneliti

\section{Pengembangan Potensi Wisata}

Pembangunan daerah merupakan proses untuk mengelola potensi dan sumber daya dengan memnebntuk pola kemitraan antara pemerintah daerah dan sector swasta oleh pemerintah daerah dan masyarakat untuk menciptakan lapangan kerja baru dan merangsang pertumbuhan ekonomi dalam wilayah tersebut (Yunas, 2019). Secara kongkrit tujuan pembangunan Kota Pekanbaru bertujuan melanjutkan pembangunan yang telah dijalankan untuk mengatasi, memecahkan masalah strategis daerah yang belum mencapai hasil maksimal (Yunas, 2019).

Selain itu, pendekatan pembangunan yang selama ini digunakan haruslah diubah. 
Pendekatan pembangunan berbasis masalah, dan menganggap kemiskinan, pengangguran, infrastruktur rusak, kenakalan remaja, minimnya lahan, pupuk mahal sebagai masalah, hanya akan menghasilkan sebuah program kerja yang berbasis kebutuhan (Rahayu, 2016). Fokus utama adalah untuk mengidentifikasi dan mencari akar masalahnya, kemudian mencari solusi terbaiknya, dan pada akhirnya ketika masalah satu selesai, akan ada upaya untuk mencari permasalahan yang lain. Sehingga tidak akan pernah mengetahui potensi besar yang bisa dikembangkan dari desa tersebut (Solikatun, Supono, \& Yulia Masruroh, 2014 dalam Yunas, 2019).

\section{Identifikasi Aktor Yang Terlibat}

Kota Pekanbaru berupaya untuk melakukan sinkronisasi kerjasama pengembangan kepariwisataan dengan berbagai pihak termasuk komunitas pelaku pariwisata di kota Pekanbaru sehingga peran masyarakat dalam mengembangkan kepariwisataan yang semakin tumbuh dan terarah berdasarkan dengan kebijakan pemerintah. Yang dimaksud Pentahelix menurut Arif Yahya adalah kolaborasi 5 (Lima Unsur) unsur subjek atau stakeholder pariwisata, yaitu: Academician (Akademisi), Business (Bisnis), Community (Komunitas), Government (Pemerintah) dan Media (Publikasi Media). Biasa disingkat ABCGM.

Pengembangan pariwisata di Kota Pekanbaru dari hasil penelitian telah menerapkan Model Pentahelix, yaitu melibatkan elemen- elemen: Akademisi, Bisnis, Pemerintah (Goverment), Komunitas (Community) dan Media Massa. Adapun narasumber atau informan yang diwawancarai dalam penelitian ini sebanyak 5 orang merupakan perwakilan dari model Pentahelix yang terdiri atas pebisnis, pemerintah, komunitas, akademisi dan media.

Pemerintah (Government) pada umumnya merupakan birokrasi dipandang sebagai agen administrasi yang paling bertanggungjawab dalam implementasi kebijakan baik di Negara maju maupun Negara berkembang (NSB). Media Massa (Media), merupakan penghubung penting antara negara dan masyarakat, perpaduan reporter pasif dan analis aktif memiliki tempat tersendiri dalam proses kebijakan publik untuk memberikan ruang bagi pemerintah dan masyarakat dalam memahami masalah sosial sekaligus untuk memecahkan permasalahan sosial tersebut. Komunitas (Community) merupakan aktor lainnya yang berperan dalam implementasi adalah kelompok atau komunitas.

Dalam implementasinya banyak dilakukan oleh birokrasi,maka banyak kelompok-kelompok yang ada di masyarakat untuk mempengaruhi berbagai peraturan implementasi seperti pedoman atau regulasi. adanya implementasi program tertentu menciptakan peluang tindakan kelompokkelompok dimaksudkan agar mereka memperoleh keuntungan. Sedangkan akademisi (Research Organization), merupakan Lembaga lain yang sering terlibat dalam implementasi kebijakan.

Banyak program-program yang dirancang untuk melaksanakan kebijakankebijakan politik yang berlabel pro pembangunan masyarakat. Bisnis (entrepreneur) seharusnya dimanfaatkan untuk mengembangkan bisnis dalam mencapai tujuan bisnis seperti: profit, people, planet, sustainability dan tumbuh berkembag dari skala mikro, kecil, menengah, hingga besar. Seharusnya sudah saatnya entrepreneur memanfaatkan konsep yang dihasilkan oleh para akademisi melalui seminar dan diskusi.

\section{Peran Aktor Yang Terlibat}

Berdasarkan hasil penelitian, dapat diketahui bahwa aktor yang terlibat dalam pengembangan pariwisata kota pekanbaru terdiri dari 5 (lima) yaitu: Pertama adalah pemerintah (Government) meliputi:

Disbudpar Kota Pekanbaru (Dinas Budaya dan Pariwisat). Kedua adalah akademisi yang tergabung pada LPPM Universitas Riau. Ketiga business adalah, meliputi BrosisPku. Keempat komunitas terdiri Genpi Pekanbaru. Kelima adalah media karena Peran media massa sangat penting dalam membangkitkan perhatian, memprovokasi aksi, melemahkan penentangan, menunjukkan kekuatan komitmen dan dukungan yakni TVRI Riau. 

Tabel 3. Aktor Yang Terlibat Berdasarkan 5 Klasifikasi Dalam Model Pentahelix

\begin{tabular}{|c|c|c|c|c|}
\hline No. & Nama Instansi & Profesi & Kegiatan & Realisasi \\
\hline 1 & TVRI & Wartawan & $\begin{array}{l}\text { Publikasi informasi kepariwisataan } \\
\text { melalui media televise Kota } \\
\text { Pekanbaru }\end{array}$ & \\
\hline 2 & $\begin{array}{l}\text { Genpi Pekanbaru } \\
\text { (Komunitas } \\
\text { Generasi Pesona } \\
\text { Indonesia) }\end{array}$ & $\begin{array}{l}\text { Komunitas } \\
\text { Pecinta Wisata }\end{array}$ & $\begin{array}{l}\text { Promosi destinasi dan event wisata } \\
\text { Kota Pekanbaru }\end{array}$ & $\begin{array}{l}\text { Sesuai peran dan aktif } \\
\text { mengadakan kegiatan } \\
\text { yang berhubungan } \\
\text { dengan pariwisat baik } \\
\text { scara langsung } \\
\text { maupun melalui sosial } \\
\text { media. }\end{array}$ \\
\hline 3 & Brosis PKU & Enterpreneur & $\begin{array}{l}\text { Promosi destinasi dan event } \\
\text { wisata Kota Semarang di pada situs } \\
\text { web dan bersifat } \\
\text { independen }\end{array}$ & $\begin{array}{l}\text { Sesuai Peran dan } \\
\text { diharapkan mampu } \\
\text { mengembangkan } \\
\text { destinasi wisata Kota } \\
\text { Peknbaru. }\end{array}$ \\
\hline 4 & LPPM UNRI & Akademisi & Lembaga research & $\begin{array}{l}\text { Sudah banyak riset } \\
\text { yang erkaitan dengan } \\
\text { pariwisata/pngelolaan } \\
\text { potensi wisata dan } \\
\text { riset sejenis lainnya. }\end{array}$ \\
\hline & $\begin{array}{lr}\text { Dinas } & \text { Budaya } \\
\text { dan } & \text { Pariwisata } \\
\text { Kota Pekanbaru }\end{array}$ & $\begin{array}{l}\text { Intansi } \\
\text { Pemerintah }\end{array}$ & $\begin{array}{lr}\text { Urusan Bidang } & \text { Kebudayaan } \\
\text {,Kesenian,Pembinaan } & \text { Industri } \\
\text { Pariwisata, Pemasaran } & \text { (Promosi) } \\
\text { Kota Pekanbaru } & \\
\end{array}$ & Sesuai Tupoksi \\
\hline
\end{tabular}

Sumber : Olahan Peneliti, 2019

Berdasarkan hasil penelitian dari tabel 3 pada bagian pembahasan menjelaskan bahwa sektor wisata ketika dikelola dengan baik, dapat meningkatkan perekonomian nasional, yakni dengan berkunjungnya turis ke Indonesia melalui penggunaan jasa transportasi, akomodasi, pembayaran tiket, oleh - oleh, memakai fasilitas restoran, hotel dan lain-lain. Dan dengan adanya kebijakan pengembangan SDM kepariwisataan diarahkan oleh akademisi ketika melakukan penelitian yang bertujuan untuk mengembangkan dan meningkatkan kualitas dan profesionalisme sumber daya manusia berbasis kompetensi.

Akademisi dapat berperan memberikan pandangan dan analisis berdasarkan objektifitas data di lapangan mengenai tingkat perkembangan dan juga formula yang tepat guna memajukan kepariwisataan melalui berbagai penelitian, analisis, serta pengembangan SDM. Adanya sumber daya manusia di industri pariwisata berperan selaku motor penggerak kelangsungan industri, serta penentu daya saing industri pariwisata. Dan yang paling utama (urgent) adalah perlunya kolaborasi pemerintah daerah dengan masyarakat sekitar dalam memberantas pemungutan liar atau preman-preman yang dapat meresahkan dan membuat wisatawan merasa tidak nyaman.

Pengembangan pariwisata di Kota Pekanbaru seharusnya tidak hanya dikelola oleh pemerintah provinsi Riau dan Kota Pekanbaru saja, namun juga dibutuhkan peran pihak swasta dan pihak lain yag mendukung melalui ide-ide dan inovasi kreatif yang bersinergi dan meliputi seluruh stakeholder di industri pariwisata, dan hal ini dapat meningkatkan kemajuan pada pariwisata Kota Pekanbaru.

Sektor pariwisata yang dikelola dengan benar dapat membuka peluang bisnis bagi warga sekitar maupun investor asing yang ingin menanamkan modal dalam pengembangan kepariwisataan di Kota Pekanbaru, selain itu industri pariwisata juga dapat berpengaruh terhadap sub sektor 
industri lain seperti bisnis valuta asing, akomodasi, restoran, transportasi, dan lainlain. Terkait dengan kolaborasi model pentahelix, disinilah peran pelaku bisnis yang paling utama yaitu perlunya kolaborasi pemerintah Kota Pekanbaru dalam memaksimalkan upaya agar wisatawan yang dating merasa nyaman.

Peran pemerintah dalam mengembangkan potensi pariwisata di diharapkan mampu memberikan kemudahankemudahan dalam pengembangan pariwisata di Indonesia melalui kebijakan yang dapat dilaksanakan serta mampu mendukung semua stakeholder di sektor pariwisata. Dalam mengelola dan mengembangkan potensi pariwisata, diperlukan suatu kordinasi dan kolaborasi antara pihak pemerintah, pihak bisnis/privat, komunitas, akademisi, serta media dalam mengembangkan potensi wisata, dimana kerjasama tersebut disebut dengan kolaborasi Pentahelix.

Penelitian ini memiliki keterbatasan antara lain keterbatasan jumlah variasi informan, dimana perwakilan dari model Pentahelix hanya diwakili satu orang informan. Diharapkan pada penelitian mendatang, untuk penelitian kualitatif diperlukan lebih banyak lagi narasumber, serta untuk penelitian kuantitatif juga dapat digunakan dalam rangka meneliti model pentahelix dalam pengembangan pariwisata di Indonesia melalui responden yang bersifat massal.

\section{SIMPULAN}

Dinas Kebudayaan dan Pariwisata di Kota Pekanbaru seharusnya melakukan perencanaan yang optimal dalam mengelola dan mengembangkan objek wisata dengan membuat suatu program yang bekerlanjutan, membuat target jangka pendek, menengah dan jangka panjang sebagai pedoman atau tolak ukur target yang akan dicapai. Dalam proses pengorganisasian Disbudpar Kota Pekanbaru perlu membuat standar operasional prosedur (SOP) dalam kegiatan pengembangan objek wisata hingga ke desa - desa yang berpotensi dan fokus melaksanakan Tupoksi sesuai bidang pengembangan pariwisata yang dilakukan dengan tujuan dapat dinilai kemajuan prestasinya sesuai standar yang telah ditetapkan.

Pada proses pengawasan yang dilakukan seharusnya lebih meningkatkan konsistensi dan pembuatan jadwal berkala sebagai bentuk pengawasan dan pengendaliannya karena selalu cenderung pada pengawasan kepentingan-kepentingan tertentu seperti adanya event-event wisata khusus yang sifatnya hanya sementara.

Fungsi penggerakan yang dilakukan Disbudpar Kota Pekanbaru tidak hanya membentuk kegiatan koordinasi dibidang pemantauan potensi objek wisata, sarana dan prasarana yang tersedia saja melainkan juga dominan fokus dalam melakukan pemberdayaan SDM yang ada di Desa/daerah berpotensi di Pekanbaru dengan memberikan berbagai pembinaan dan pelatihan, mendatang tenaga ahli untuk memberikan pengetahuan khusus pada masyarakat. Pemerintah Kota Pekanbaru melalui Disbudpar harus lebih kreatif dalam mendapatkan dukungan, harus lebih mampu membuat mereka tertarik dan harus lebih meningkatkan kerjasama dengan ke 5 stakeholder berdasarkan model pentahelix demi terwujudnya Pekanbaru Smart City Madani.

\section{DAFTAR PUSTAKA}

Aribowo, H., Wirapraja, A., \& Putra, Y. D. (2019). Implementasi Kolaborasi Model Pentahelix Pariwisata Di Jawa Timur Serta Meningkatkan Perekonomian Domestik. Jurnal Mebis, 31-38.

Creswell, J. W. (2016). Research Design Pendekatan Kualitatif, Kuantitatif, dan Mixed. Yogyakarta: Pustaka Belajar.

Bungin, Burhan. (2008). Metodologi Penelitian Kualitatif. Jakarta: Raja Grafindo Persada.

Gde, P., \& Diarta, k. s. (2009). Pengantar Ilmu Pariwisata. Yogya: Andi Publishing.

Halibas, et.al. Maata,(2017). The Pentahelix Model of Innovation In Oman : An Hei Perspective. Interdisciplinary Journal of Information, Knowledge, and Management. Volume 12. Informing Science Institute

Ismayanti. (2011). Pengantar Pariwisata. Jakarta: Grasindo

Prihati. (2017). Implementasi Kebijakan Promosi Pariwisata Kota Pekanbaru Dalam Pengembangan Potensi Wisata Di Provinsi Riau, Research Report Disertasi, Universitas Pasundan 1-24. 
Resa Vio Vani, Sania Octa Priscilia \& Adianto, Model Pentahelix dalam Mengembangkan Potensi Wisata

Rahayu, S., Dewi, U., \& Fitriana, kurnia nur. (2016). Pengembangan Community Based Tourism Sebagai Strategi Pemberdayaan Ekonomi Masyarakat Di Kabupaten Kulon Progo, Daerah Istimewa Yogyakarta. Jurnal Penelitian Humaniora, 21(1), 1-13.

Rencana Strategis (Renstra) 2014-2019. http://pariwisata.riau.go.id

Rencana Kerja Perangkat Daerah Riau Tahun 2019

Soemaryani Imas. (2016). Pentahelix Model To Increase Tourist Visit To Bandung And Its Surrounding Areas Through Huan Resource Development. Journal Academy of Strategic Management.Volume 15, Special Issues 3,

Peraturan Daerah nomor 13 tahun 2000 tentang Promosi Pariwisata Daerah Kota Pekanbaru

Undang-Undang Nomor 33 tahun 2004 tentang Perimbangan Keuangan antara Pusat dan Daerah pasal 1 angka 18 dikatakan Pendapatan Asli Daerah

Yunas, S.N. (2019). Implementasi Konsep Penta Helix dalam Pengembangan Potensi Desa melalui Model Lumbung Ekonomi Desa di Provinsi Jawa Timur. Matra Pembaruan, 3(1), $37-46$. https://doi.org/10.21787/mp.3.1.2019.3746 